\title{
DSP Based Testing Platform for Characterization of BLDC Motor Performance Using TMS320F28069
}

\author{
Vinay Kumar Awaar ${ }^{1}$, Rajshri Simhadri ${ }^{1}$, Venkatesh Chityala ${ }^{1}$, and Praveen Jugge ${ }^{1}$
}

${ }^{1}$ Department of EEE, GRIET, Hyderabad, India

\begin{abstract}
This paper presents a framework to carry out the BLDC motor characteristics using code composer studio software interfaced with a GUI named InstaSpinBLDC. The three phase BLDC motor is driven with DRV8312 and a control card TMS320F28069 is used to run the sensor InstaSpin BLDC. This proposed work is intended to track the dynamic performance and lower the minimum operating speed with respect to control modes. Four control modes have been modelled in conjunction of three phase inverter for BLDC motor. The simulation includes all realistic values and components of the motor. Three-phase inverter and its control algorithm are modeled and simulated using MATLAB Simulink. Hardware results have been presented along with the simulation results.
\end{abstract}

\section{Introduction}

In EVs and many other applications, we require a wide range of speed and torque control. Electric motors are an important source of industrial plants. Although we find that in many appliances, the machines used are singlephase IM or brushed DC motors; they are low efficient and high maintenance, respectively. Therefore, by replacing the motor with efficient BLDC motor will be beneficial for saving of the energy. Because of the absence of brushes and electronic commutation, BLDC motors are efficient. In every industry, some processes require change of normal speed similarly various methods are there for speed control of BLDC motor like PWM technique, sensor-less control, etc. In this paper the modeling of the three-phase inverter is designed for operating the BLDC motor using MATLAB simulation, and hardware is implemented, and we introduced a technique to control a BLDC motor using duty cycle resolution and the rotor position which is estimated using sensor and sensorless techniques.

The control method for low speed sensor less operation of BLDC motors is built on BEMF reconstruction was presented in [6]. The PWM control is the most power full technique that offer a simple method for controlling of analog system with processors digital output. PWM frequency depends on the target Field programmable gate arrays device speed and duty cycle resolution requirement. In this paper, BLDC motor drive controlled using FPGA controller.[12]

\section{Three-Phase Inverter}

Three-phase inverter is used in the conversion of DC voltage to three-phase AC supply. Figure 1 represents the circuit diagram of a three-phase bridge inverter which consists of six diodes and six thyristors. A threephase inverter for a BLDC speed control comprises generating DC currents in motor phases. The required switching was done by using a microcontroller in this paper we used F28069. Necessary gate driver circuit is required for proper operation of the inverter. The most frequently used circuit of a three-phase inverter is that it comprises three terminals and, in this method, we connect the load in star, to eliminate the harmonics multiples of three $(n=3,6,9 \ldots)$. Output voltage of an inverter is independent of load current direction. The three-phase inverter or single-phase is operated in two modes of operation: 180 degrees and 120 degrees conduction mode.

For 180 degrees conduction, every device is at 180 conductions, and it is activated with 60-degree interval. As shown below the output phases $\mathrm{A}, \mathrm{B}$ and $\mathrm{C}$ are connected in a star or delta pattern to the load. For 0 to 60 degrees, the switches Q1, Q5 and Q6 are in conduction mode. $\mathrm{A}$ and $\mathrm{C}$ phases are connected to positive point and $\mathrm{B}$ is connected to negative point. For 120 degrees conduction, every device is at 120 conductions, this mode is suitable for delta connection

\footnotetext{
* Corresponding author: vinaykumaar.a@gmail.com
} 
with the load because it results in a six-step waveform, here the connection of terminal $\mathrm{A}$ is at the positive end through load, similarly $\mathrm{B}$ on the negative end and $\mathrm{C}$ is left unconnected this particular state is called as floating phase.

\subsection{Pulse Width Modulation}

The method used in this paper is sinusoidal pulse width modulation they consist of a sinusoidal waveform with a duty cycle. Based on the SPWM method we can control the speed of BLDC motor in which the actual speed can be obtained in open loop configuration. This method usually involves two types of waveforms namely reference wave $(\mathrm{Fr})$ and carrier wave $(\mathrm{Fc})$. Here the reference wave is a sinusoidal wave having fundamental frequency of about $50 \mathrm{~Hz}$, and carrier wave is a triangular waveform having high frequency in order of $\mathrm{kHz}$.

The switching frequency of the inverter increases as the frequency of Fc wave is increased, the inverter's output frequency is determined by Fr. The output which is obtained is compared with Fc and Fr and the modulation index is determined. Here the modulation index can control the fundamental frequency of output voltage. Modulation Index $\mathrm{Ma}=\mathrm{Vm} / \mathrm{Vcr}$.

\subsection{Working of BLDC motor}

A BLDC motor is driven by DC current, it has a permanent magnet and runs with a synchronous speed also it comes with an advantage of electronic commutation instead of a regular commutation. For the electronic commutation it should energize the stator windings in a sequence and to detect the rotor's position. Here with the help of Hall Effect sensors the position of rotor is determined. These hall sensors are placed inside the motor each phase i.e. u, v, w being 120 degrees apart the hall sensor here provides the required output and determines whether the output is high or low which is based on the magnetic pole's polarity which is close to it.

For every 60 degrees apart, we observe a change in the state of hall sensor. The sequence of the conducting phases and activation of switches and hall sensor positions can be obtained using the table below. The advantage of this technique is that the motor can be run at very low speeds and the algorithm are easy to understand. Here the figure 1 represents a three-phase inverter containing three hall sensors along with six switches namely Q1, Q2, Q3, Q4, Q5, and Q6 as shown and table 1 denotes switching activation and enables to detect the position of hall sensor.

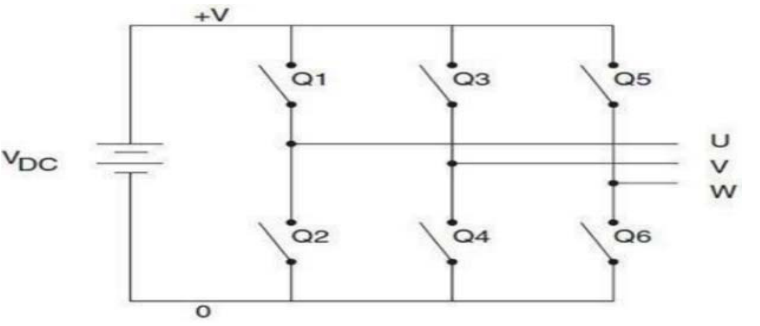

Fig. 1. Three-phase Inverter with three hall sensors

Table 1. Hall sensors vs switching positions

\begin{tabular}{|c|c|c|}
\hline Phase & Hall sensors & switches \\
\hline U, V & 101 & Q1, Q4 \\
\hline U, W & 001 & Q1, Q6 \\
\hline V,W & 011 & Q3, Q6 \\
\hline V, U & 010 & Q3, Q2 \\
\hline V, W & 110 & Q5, Q2 \\
\hline W, V & 100 & Q5, Q4 \\
\hline
\end{tabular}

\subsection{Indirect back-emf technique (sensor less)}

The performance of Integrated back Emf is better than the zero-crossing method (or direct back emf technique) the modified back-EMF wave is supplied to the integrator, the need of an integrator here is to decrease switching noise by automatically adjusting the switching sequence of an inverter which also helps in changing the rotor's speed accordingly and the output obtained here is again compared with the adjusted threshold value.

\section{Simulation results}

The three phase BLDC motor relates to the inverter. For detecting the rotor's position, we require hall sensors. We also require gate pulses, which are to be fed back again to the inverter, this is only possible with the help of decoder which detects the pins position and changes the emf values to positional emf. Figure 2 represents the MATLAB simulation of a bldc motor for the speed control.

Fig 3. represents the PMW pulses that are observed in a way that the average highs and lows obtained are proportional to the applied input, without a filter. Fig 4. represents the inverter output without the filter, which gives a smooth AC output curve when supplied a DC input. Fig.5. and Fig. 6 indicate the inverter output voltage with a filter, here basically a filter is used to limit to decrease the amount of output voltage obtained and used to increase the quality of power obtained by reducing the harmonics. Fig. 7 indicates the speed 
control of BLDC motor which can be as shown in the figure is a linear graph.

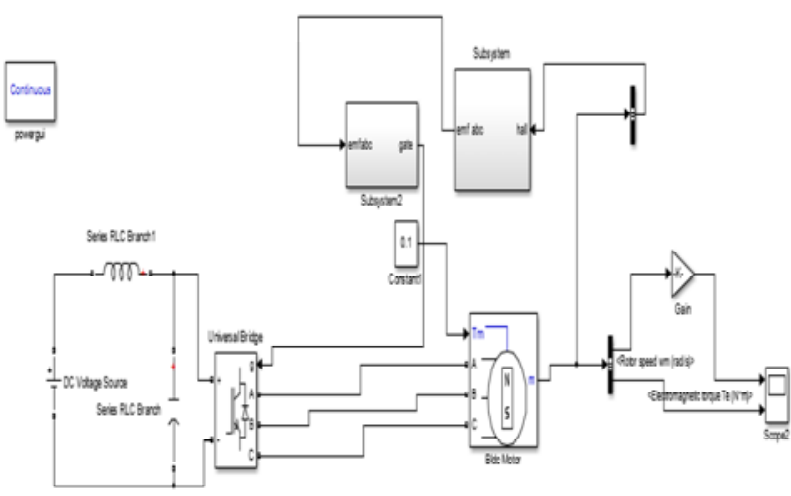

Fig. 2. Three-phase Inverter three phase inverter with three hall sensors

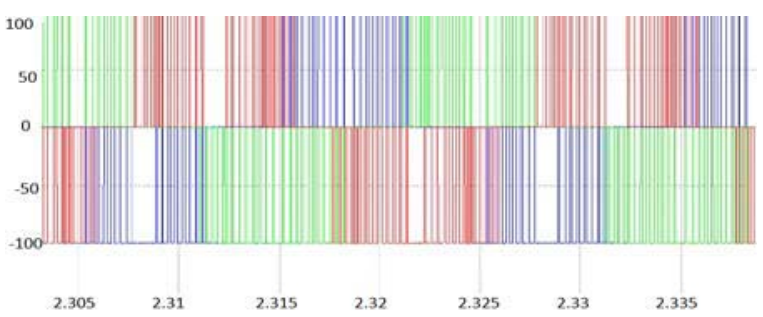

Fig. 3. PWM pulses

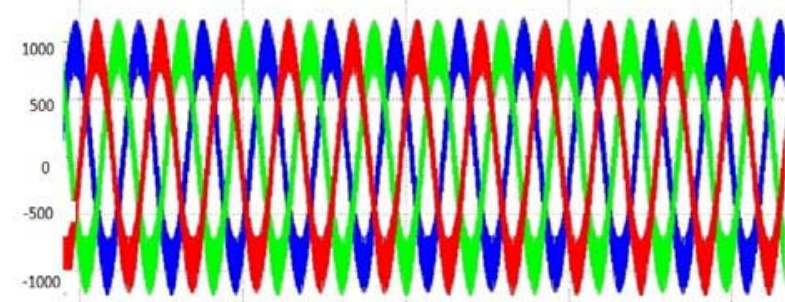

Fig. 4. Inverter output without filter

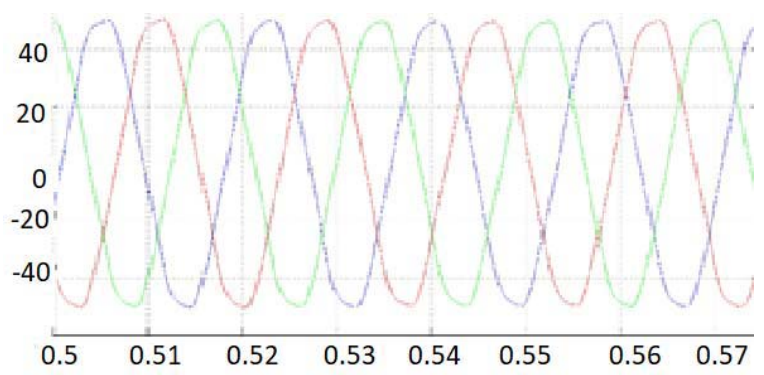

Fig.5. Inverter output voltages without filter

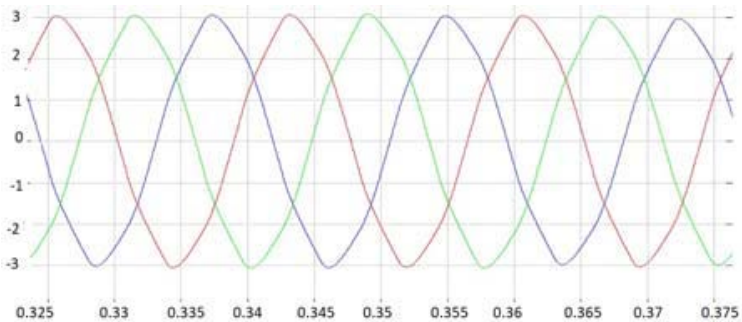

Fig.6. Inverter output current without filter

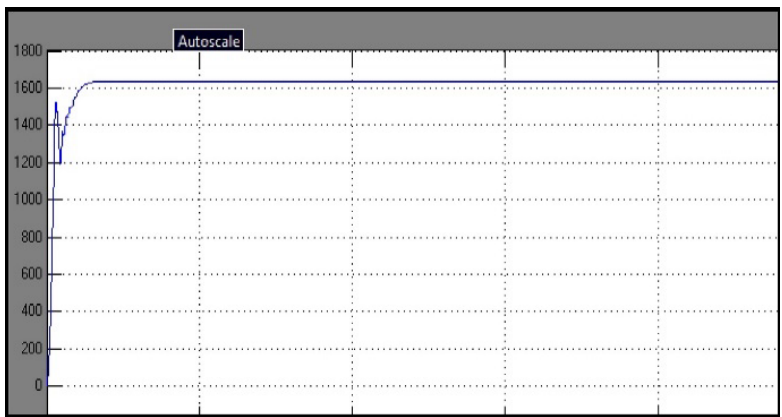

Fig.7. Speed curve

Fig.3 through Fig.7 represents output waveforms of a three phase inverter.

\section{EXPERIMENTAL RESULTS}

The performance characteristics of the BLDC motor includes a control card F28069, and a digital control DRV8312 (evaluation module) with a medium voltage. The DRV8312 board power is categorized into two powers i.e controller power and Dc bus power Controller power. The board requires a power supply of $24 \mathrm{v}$, it has a medium-voltage dc bus voltage $52.5 \mathrm{~V}$ with a $6.5 \mathrm{~A}$ peak current and of $3.5 \mathrm{~A}$ continuous current. The frequency limit is $500 \mathrm{kh}$. Reset switch is operated for each half-bridge; the reset disables the output from each half-bridge and when the switch is set to the middle position it will allow to control. The control card used is TMS320F28069F that consists of 100 pin packages with a fast estimator used to determine motor control, functions of speed, efficiency to drive the three-phase brushless DC motor and it requires a power supply of $3.3 \mathrm{v}$, operates at frequency $2 \mathrm{MHZ}-90 \mathrm{MHZ}$.

\subsection{Duty Cycle}

By varying duty cycles we can achieve the speed control of the BLDC motor. Here the knob functions as the PWM pulses for the motor. By changing the flux accordingly, we need to rotate the motor throughout the duty cycle. In figure 9 the knob functions to various duty cycle and the speed ranges are observed. When the motor is loaded, we observe no control loop for the speed regulation and gradually the motor runs down. In 
Table 2 the speed variation with the respective duty cycle is shown.

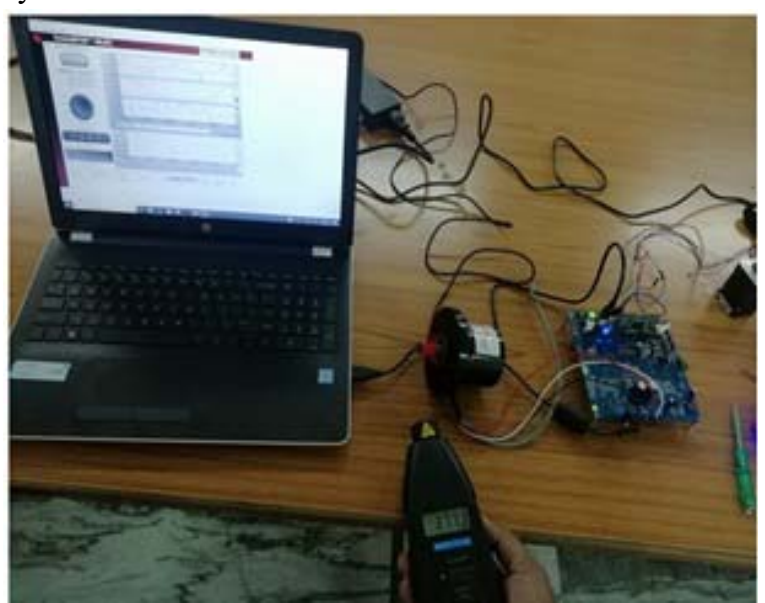

Fig.8. MATLAB DRV8312 hardware with BLDC motor along with control card (hardware implémentation).

Table 1. Flux, voltage, current, and speed values with respective speed.

\begin{tabular}{|c|c|c|c|c|}
\hline $\begin{array}{c}\text { Control } \\
\text { value }\end{array}$ & Flux & Voltage & Current & Speed \\
\hline 0.2 & 0.395 & 0.2173 & 0.0347 & 608 \\
\hline 0.4 & 0.378 & 0.2594 & 0.0596 & 1222 \\
\hline 0.6 & 0.396 & 0.2971 & 0.0821 & 1836 \\
\hline 0.8 & 0.399 & 0.3247 & 0.1343 & 2456 \\
\hline
\end{tabular}

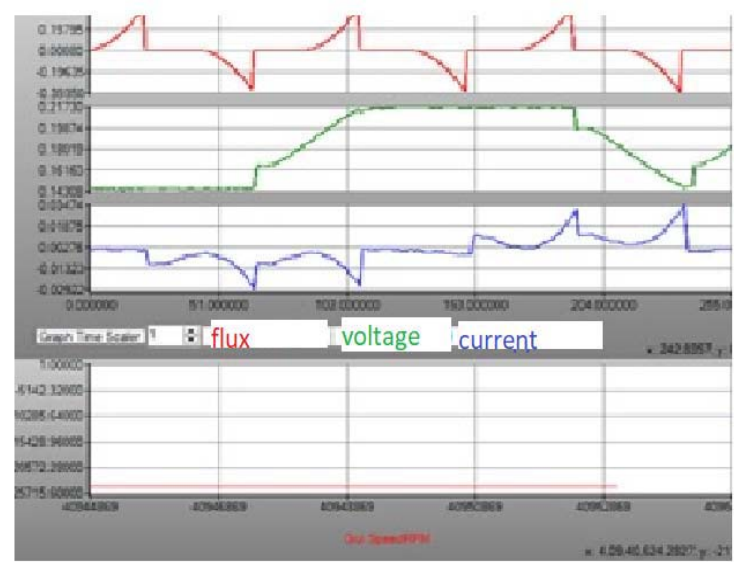

Fig.9. Duty cycle mode

\subsection{Velocity control mode}

The velocity control mode is used to control the speed using the PI controller, in this control mode the difference of original speed and required speed are given as the input to PI controller and characteristics are shown in figure 10 .
As shown in below table 3, we observe that there is a variation of velocity values from 0.2 to 0.8 the voltage increases with respective to current the flux remains constant the duration of speed remains constant.

Table 2. Flux, voltage, current, and speed values with respective speed

\begin{tabular}{|c|c|c|c|c|}
\hline $\begin{array}{c}\text { Control } \\
\text { value }\end{array}$ & Flux & Voltage & Current & Speed \\
\hline 0.2 & 0.397 & 0.2159 & 0.0320 & 4648 \\
\hline 0.4 & 0.397 & 0.2523 & 0.0559 & 4650 \\
\hline 0.6 & 0.396 & 0.2947 & 0.0808 & 4650 \\
\hline 0.8 & 0.395 & 0.3238 & 0.11404 & 4650 \\
\hline
\end{tabular}

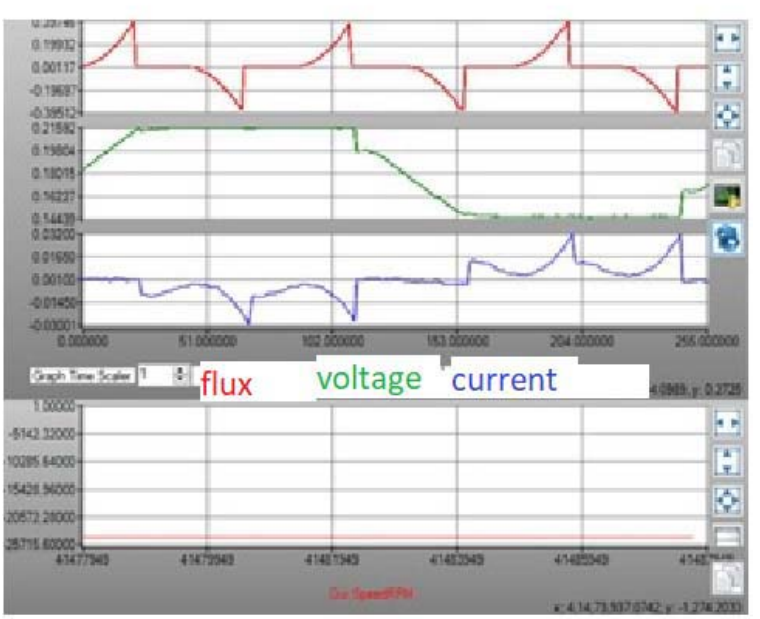

Fig.10. Velocity control mode

\subsection{Current control mode}

In this control mode the current is regulated. We observe the parameters to be active only in current or cascade mode. Here $\mathrm{Kp}$ and $\mathrm{Ki}$ are proportionality gain and integral gain of the current controller respectively. The knob function is used to set the commanded current through the motor. The knob is adjusted to 0.4 commanded current.

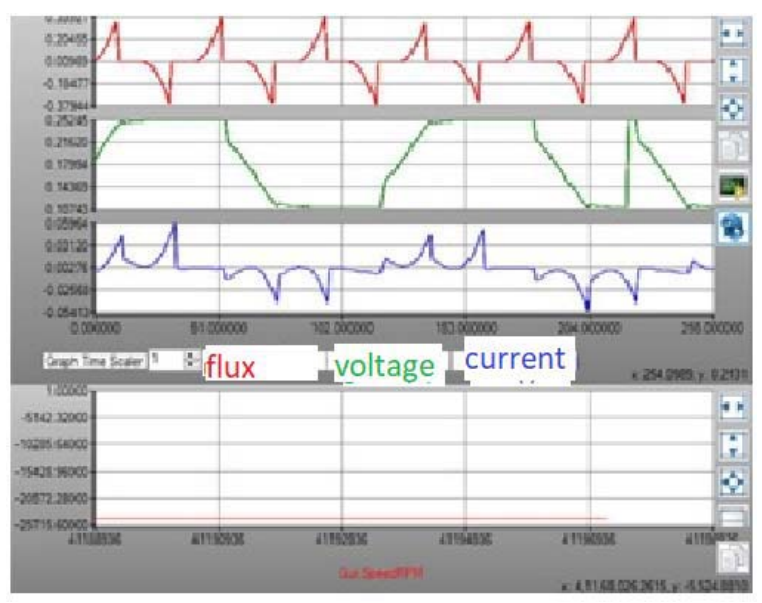

Fig.11. Current control mode 
Here, we observe commutation at low speed because the motor is also running at a low speed. Speed is observed by varying the knob function the current is controlled. The characteristics are shown in above figure $4 \mathrm{c}$, the set values of current command and speed. The speed increases with torque. In the table 4 , due to variation of current values from 0.2 to 0.8 the current increases with respect to the voltage the flux remains constant the duration of speed remains constant. In four modes cascade control mode is better when compared to various modes. In this mode both velocity and current are controlled. The speed is maintained constant.

Table 3 Flux, voltage, current, and speed values with respective speed

\begin{tabular}{|c|c|c|c|c|}
\hline $\begin{array}{c}\text { Control } \\
\text { value }\end{array}$ & Flux & Voltage & current & speed \\
\hline 0.2 & 0.399 & 0.2168 & 0.0308 & 4648 \\
\hline 0.4 & 0.399 & 0.2524 & 0.0596 & 4650 \\
\hline 0.6 & 0.392 & 0.2944 & 0.0738 & 4650 \\
\hline 0.8 & 0.377 & 0.3239 & 0.1158 & 4650 \\
\hline
\end{tabular}

Here we observe that in both the current control mode and velocity control mode the flux values are not varying much hence there no large variation in the speed observed also.

\subsection{Cascade control mode}

Cascade mode controls both velocity and current. In this mode the speed of the motor is regulated by PI controller the output obtained is current command which is again regulated by low-current-level PI controller. Here the knob adjusts the motor commanded speed, the knob is adjusted to 0.8 the motor current has increased the flux, current, voltage waveforms are observed as shown in below figure $4 \mathrm{~d}$. Because of variation of cascade values from 0.2 to 0.8 the current increases with voltage, flux and the duration of speed remains constant as shown in table 5 .

Because of variation of cascade values from 0.2 to 0.8 the current increases with voltage, flux and the duration of speed remains constant.

Here in from fig $4 d$ we can say that we observe a uniform velocity and current curves whereas in the other control modes there is no uniformity observed in the graphs, and table 5 when observed we find there a constant speed hence cascade control mode is efficient and beneficial.

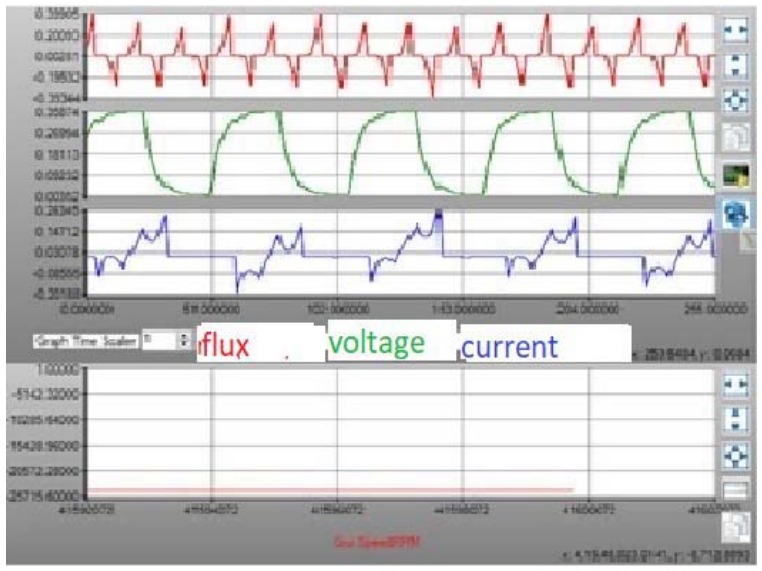

Fig.12. Cascade control mode

Table 4 Flux, voltage, current, and speed values with respective speed

\begin{tabular}{|c|c|c|c|c|}
\hline $\begin{array}{c}\text { Control } \\
\text { value }\end{array}$ & Flux & Voltage & Current & Speed \\
\hline 0.2 & 0.390 & 0.2161 & 0.0334 & 4650 \\
\hline 0.4 & 0.383 & 0.2530 & 0.0608 & 4650 \\
\hline 0.6 & 0.393 & 0.2969 & 0.0818 & 4650 \\
\hline 0.8 & 0.388 & 0.3235 & 0.1428 & 4650 \\
\hline
\end{tabular}

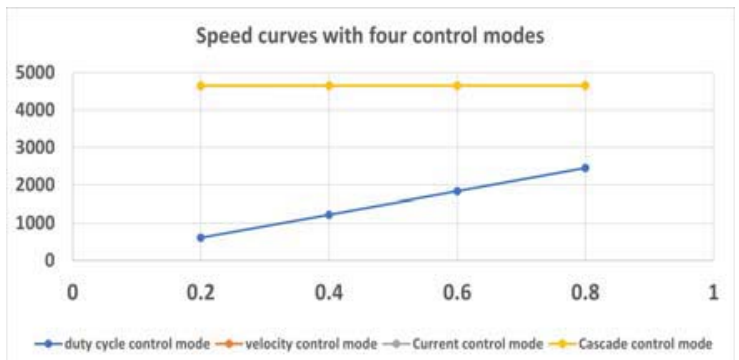

Fig.13. Speed curves of four control modes

Here figure 13, represents the four modes where the velocity, current and cascade mode overlap with each other. Although they overlap the cascade control mode is efficient as we observe constant values in the speed of the BLDC motor.

\section{Conclusions}

This study has successfully determined and developed a method to control the speed of the BLDC motor. Here, three phase inverter for BLDC motor has been modelled using MATLAB Simulink. The speed of a BLDC is controlled by using module drv8312 with a control card TMS320F28069 with GUI implementation. The BLDC motor is fed with three phase inverters with SPWM technique modelling, and a control card is used to run the sensor InstaSpin BLDC. The testing platform for the characterization of the BLDC motor is achieved and its performance is compared with the four modes of speed control. 


\section{References}

[1] R. Zhang, M. Cardinal, P. Szczesny and M. Dame, 2002 IEEE 33rd Annual IEEE Aust,3, (2002).

[2] Johnson, J.P.; Ehsani, M.; Guzelgunler IEEE Indus Appl Conf ,( 1999).

[3] T.J.E Miller, Oxford University press (1989).

[4] Dwivedi and A. N. Tiwari, IJBSTR, 1, 6, (2013).

[5] M. Markovic, A. Holder, Y. Perriard, IEEE, Energy Conv Cong and Exp, (2009)

[6] Carlo Concari, Fabrizio Troni IEEE Conf pub.

[7] R. Gambhir and A. K. Jha Int. J. Eng. Sci., 2,5, (2013).

[8] Miroslav Markovic and Yves Perriard, IEEE, 42, 12,( 2006).

[9] Salih Baris, Ozturk Hamid A. Toliyat IEEE, (2007).

[10] V. Khadkikar, A. Chandra and B. N. Singh, IET Pow electronics, 2, 1, (2009)

[11] Awaar, V.K., Jugge, P. \& Tara Kalyani, S. J Control Autom Electr Syst 30, (2019).

[12] Pindoriya, Rajesh M., S. Rajendran, and P. J. Chauhan (2014).

[13] B. J. Varghese, P. B. Bobba and M. Kavitha IEEE, PIICON (2016).

[14] Kavitha, Merugu; Prasad, Dinkar; Bobba, Phaneendra Babu, IET 13,8 (2008).

[15] M. Kavitha, P. B. Bobba and D. Prasad, IEEE, ICPS(2016). 